\title{
Effects of process parameters and geometry on dimensional accuracy and surface quality of thin strut heart valve frames manufactured by laser powder bed fusion
}

\author{
Xiao Zhao ( $\nabla$ xiao.zhao@soton.ac.uk) \\ University of Southampton https://orcid.org/0000-0002-9714-3176 \\ Anqi Liang \\ University of Southampton \\ Matteo Bellin \\ SISMA S.p.A., Via dell'Industria \\ Neil W. Bressloff \\ University of Southampton
}

\section{Research Article}

Keywords: transcatheter aortic valve implementation (TAVI), laser powder bed fusion (LPBF), process parameters, dimensional accuracy, surface quality

Posted Date: January 28th, 2022

DOI: https://doi.org/10.21203/rs.3.rs-1271909/v1

License: (c) (i) This work is licensed under a Creative Commons Attribution 4.0 International License.

Read Full License 


\title{
Effects of process parameters and geometry on dimensional accuracy and surface quality of thin strut heart valve frames manufactured by laser powder bed fusion
}

\author{
Xiao Zhao ${ }^{a^{*}}$, Anqi Liang ${ }^{b}$, Matteo Bellin ${ }^{c}$, Neil W. Bressloff ${ }^{\text {a }}$ \\ a School of Engineering, Faculty of Engineering and Physical Sciences, University of Southampton, \\ Boldrewood Innovation Campus, Southampton, SO16 7QF, UK \\ b School of Engineering, Faculty of Engineering and Physical Sciences, University of Southampton, \\ Highfield Campus, Southampton, SO17 1BJ, UK \\ c SISMA S.p.A., Via dell'Industria, 1-36013 Piovene Rocchette (VI), Italy \\ *Corresponding author,email: xiao.zhao@soton.ac.uk
}

\begin{abstract}
:
Laser powder bed fusion (LPBF) is one of the most popular metal additive manufacturing technologies, which has found its applications in high-value sectors such as aerospace and biomedical devices. Some recent studies on the LPBF of stents have demonstrated its feasibility in the fabrication in thin strut structures including heart valve frames, as used in transcatheter aortic valve implantation (TAVI) for the treatment of severe aortic stenosis. The state of the art method of laser cutting TAVI frame limits the scope for novel concepts which are made possible by additive manufacturing. However, the surface quality and dimensional accuracy of LPBF parts are lower than that produced by laser cutting. To start the development of new TAVI concepts, the feasibility of manufacturing thin frames by LPBF has been investigated based the SAPIEN 3 frame by Edwards Lifesciences. In this study, simplified frames with strut size from $0.3 \mathrm{~mm}$ to $0.5 \mathrm{~mm}$ have been successfully manufactured. The effects of strut size, strut angle, laser power and scan speed on the dimensional accuracy and surface quality were systemically studied. In addition, a representative SAPIEN 3 frame was manufactured and assessed with high resolution X-ray scans. Good overall dimensional accuracy and low porosity was obtained for the SAPIEN 3 frame. However, inclined struts were found to have relatively low dimensional accuracy and poor surface quality.
\end{abstract}

Key words: transcatheter aortic valve implementation (TAVI); laser powder bed fusion (LPBF); process parameters; dimensional accuracy; surface quality 


\section{Introduction}

Laser powder bed fusion (LPBF) is one of the most popular metal additive manufacturing technologies. LPBF applies a high energy laser to melt particles in a thin powder layer to produce three-dimensional parts. Compared to conventional subtractive manufacturing methods, LPBF can produce metallic parts with extremely high structural complexity. Currently, a wide range of metal materials can be processed by LPBF including stainless steel, titanium, titanium alloys, nitinol, aluminium, aluminium alloys, metal matrix composites [1-3]. LPBF parts typically have high density and fine microstructures, leading to excellent mechanical properties which could be equivalent to that of wrought parts [4]. Thus, LPBF has found its applications in high-value sectors such as aerospace [5, 6] and biomedical devices [7-9].

Although LPBF has many advantages over the conventional manufacturing methods, there are several major drawbacks, such as large surface roughness [10] and low dimensional accuracy [11], which reduce its popularity in wider applications, especially fabrication of fine-sized products (structure features under $1 \mathrm{~mm}$ ). Most of the current literature relating to surface roughness are based on large bulk parts. It was reported that the surface finish is directly affected by process parameters, such as laser energy density, building orientation and layer thickness [12]. Khorasani et al. [13] studied the effects of laser power, scan speed, hatch space, scan pattern angle and heat treatment temperature on the top surface roughness of LPBF Ti-6Al-4V parts via an experiment using the Taguchi method. The results showed that ranking of the most to the least effective parameters was obtained as heat treatment $>$ hatch space > scan speed > laser power > scan pattern angle. Meanwhile, the authors suggested that a combination of higher laser power and lower scan speed produces higher temperatures to reduce the surface tension of melt pool, an effect which could improve the surface quality. Guo et al. [14] investigated effects of laser power, scan speed and hatch space on surface roughness of as-built IN738LC parts via LPBF. The top surface roughness was obtained between Ra $11 \mu \mathrm{m}$ and Ra $28 \mu \mathrm{m}$. A minimum surface roughness was obtained with a specific combination of process parameters. The surface became rougher with higher energy density combinations as more mass was transferred to the previously fabricated tracks due to more vigorous Marangoni flow. The surface roughness increased significantly with low energy density combinations since increasing numbers of open pores were formed as well as the presence of many un-melted particles. Snyder and Thole [15] explored the influence of hatch space and contour scan on the roughness of both the up-skin and down-skin surfaces. The results showed the roughness of down-skin surface had higher magnitudes than the up-skin surface (up to $25 \mu \mathrm{m}$ ). They believed that the roughness of up-skin surfaces was tied to the overall size of the melt pool, while the down-skin surfaces were more sensitive to the melt pool depth. Fox et al. [16] reported the roughness of down-skin surfaces increased greatly with smaller overhanging angles. Calignano [17] found downward faces could be successfully built without supports at an angle up to $30^{\circ}$ (between surface and horizontal plane) but with a much higher surface roughness and structure deformation. 
Dimensional accuracy is another critical issue to consider in the LPBF of fine-sized parts. Tomas et al. [18] investigated the dimensional accuracy of thin wall, circular $\mathrm{H} 13$ tool steel parts ( $1 \mathrm{~mm}$ thickness, diameters of $25-85 \mathrm{~mm}$ ) with stripe and sectional scan strategies. All the parts were oversized with a dimensional error ranging from $0.1 \mathrm{~mm}$ to $0.5 \mathrm{~mm}$ compared to the nominal diameters. Meanwhile, the dimensional error increased along the building height from the base plate. Ahmed et al. [19] fabricated thin-walled AlSi10Mg parts with a thickness from $0.5 \mathrm{~mm}$ to $5 \mathrm{~mm}$. They found both the dimensional error and sample distortion increased with decreasing wall thickness. The sample with design thickness of $0.5 \mathrm{~mm}$ had a $2.4 \%$ error for actual thickness and $158.62 \%$ distortion rate. Charles et al. [20] studied the dimensional error in $45^{\circ}$ down-facing surfaces with different process parameters. The study indicated laser power was the most significant factor, followed by layer thickness, scan speed and then the interaction effect of laser power and scan speed. The dimensional error was between $4 \%$ and $30 \%$. $\mathrm{Wu}$ et al. [21] explored the fabrication limits of thin-wall structures from Ti-6Al-4V, AlSi10Mg and Inconel 718. The target thickness was set as between $0.1 \mathrm{~mm}$ and $0.5 \mathrm{~mm}$, with inclined angles of $30^{\circ}$, $45^{\circ}$ and $60^{\circ}$. The results showed the minimum thicknesses for Ti-6Al-4V, AlSi10Mg and Inconel 718 were $99 \mu \mathrm{m}, 101 \mu \mathrm{m}$ and $107 \mu \mathrm{m}$, respectively. The maximum inclined angle of $60^{\circ}$ can be achieved with specific process parameters.

Generally, for small dimensions which can only be achieved by single-bead mode, the wall thickness is controlled by the melt pool size instead of the CAD design. For larger sizes, achievable by both single-bead mode and raster mode, the final dimensional accuracy is related to the compensation setting of scan strategy, inclined angle as well as the material used.

Since recent research $[22,23]$ has reported that thin stent structures can be successfully fabricated via LPBF, it raises new opportunities in the fabrication of heart valve frames, which have similar thin strut structures. Transcatheter aortic valve implantation (TAVI) devices - designed for the minimally invasive treatment of a failing aortic valve - typically comprise a stent like frame and a bioprosthetic valve. The device is commonly delivered into the degenerated valve through femoral access, and then deployed via balloon expansion or self-expansion [24]. State of the art TAVI frames are fabricated by laser cutting from metallic tubes. Fig.1 depicts the balloon expandable SAPIEN 3 (S3) valve from Edwards Lifesciences. The S3 frame has a 4-layer structure and 12 cells with thin Cobalt-Chromium struts, approximately $0.3 \mathrm{~mm}$ thickness. The inclined struts have an angle approximately $55^{\circ}$ with the vertical direction. The structure provides enough radial strength to push aside the native valve and can be easily crimped and expanded. The key features of the heart valve frame such as strut thickness and inclined angles are close to the fabrication limits of LPBF, suggesting that improvements are needed in LPBF and/or the geometry of the frame needs to be modified to achieve acceptable quality. However, Melancon et al reported there are $49 \%$ and $41 \%$ mismatches between original CAD design and LPBF 
porous biomaterials for compressive elastic modulus and yield strength due to the large dimensional errors [25]. The capability of LPBF to produce thin strut structure must be fully understood as the baseline in the novel design for heart valve via LPBF.

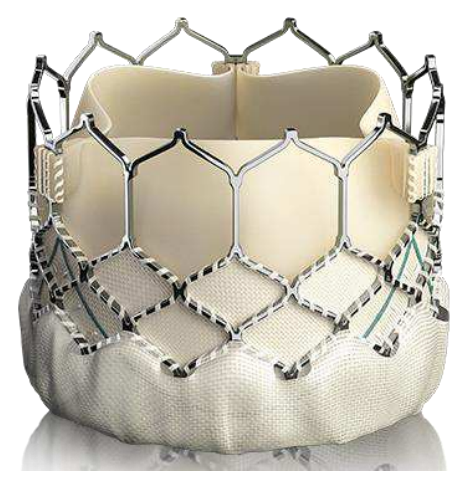

Figure 1. SAPIEN 3 heart valve. Courtesy of Edwards Lifesciences.

Recently, we demonstrated that a valve frame manufactured by LPBF could be successfully crimped and expanded [26]. Encouraged by these results, a detailed analysis was conducted on several test models based on the S3 frame. Measurements were made to assess (i) the effect of strut angles and process parameters on the manufacturing quality of these thin strut structures, (ii) the dimensional accuracy and surface morphology of the frames and (iii) the geometric accuracy of a complete S3 style frame using a high-resolution computer tomography (CT) scan.

\section{Material and methods}

\subsection{Preparation of CAD models}

The CAD models used in this study were based on the S3 frame (Edwards Lifesciences). Rhino software (Robert McNeel \& Associates, US) was used to generate the CAD models with a parametric design method via Python scripting. Fig.2a shows a 2D sketch of the S3 frame with its four-layer cell structure. The key features of different layers are illustrated in Fig.2 b-d. More details are listed in Table 1.

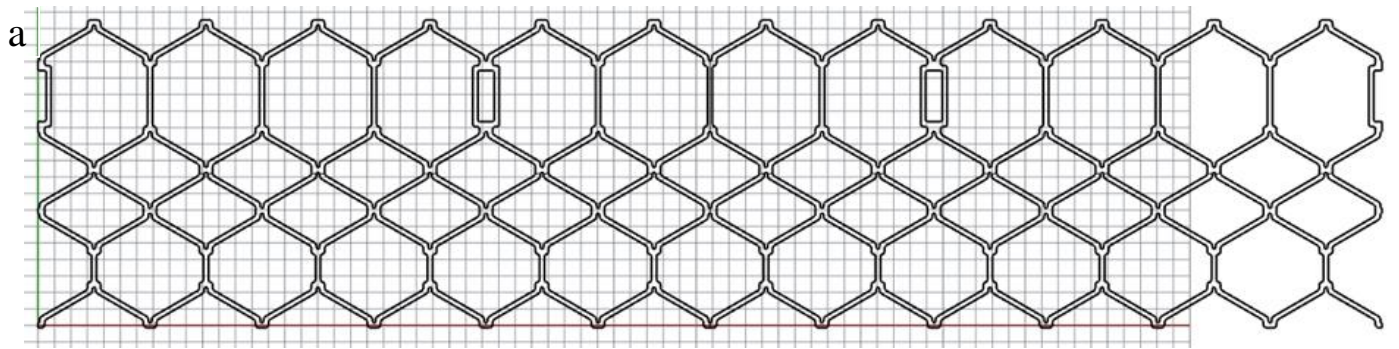






Figure 2. (a) 2D sketch of S3 type frame, and key features of (b) $1^{\text {st }}$ layer, (c) $2^{\text {nd }}$ and $3^{\text {rd }}$ layers, (d) $4^{\text {th }}$ layer and (e) 3D model of the complete frame generated in Rhino.

Table 1. Key features of the S3 frame.

\begin{tabular}{|c|c|c|c|}
\hline \multicolumn{2}{|l|}{ Key features } & \multicolumn{2}{|l|}{ Key features } \\
\hline strutWidth (mm) & The width of the struts & $\begin{array}{l}\text { strutLowVert } \\
(\mathrm{mm})\end{array}$ & $\begin{array}{l}\text { The length of vertical struts } \\
\text { of the } 1^{\text {st }} \text { layer cell }\end{array}$ \\
\hline strutThick (mm) & $\begin{array}{l}\text { The thickness of the } \\
\text { struts }\end{array}$ & $\begin{array}{l}\text { strutHighVert } \\
(\mathrm{mm})\end{array}$ & $\begin{array}{l}\text { The length of vertical struts } \\
\text { of the } 4^{\text {th }} \text { layer cell }\end{array}$ \\
\hline strutAngle & The angle between & $\begin{array}{l}\text { slotWidth } \\
(\mathrm{mm})\end{array}$ & $\begin{array}{l}\text { The width of the leaflet } \\
\text { assembly slot }\end{array}$ \\
\hline & $\begin{array}{l}\text { inclined strut and vertical } \\
\text { direction }\end{array}$ & intRia (mm) & The radius of small fillet \\
\hline & & extRia (mm) & The radius of large fillet \\
\hline $\begin{array}{l}\text { valveRadius } \\
(\mathrm{mm})\end{array}$ & The radius of the frame & $\begin{array}{l}\text { crownOffset } \\
(\mathrm{mm})\end{array}$ & The offset height of crown \\
\hline
\end{tabular}

Two batches of single-layer test models (TMs) were generated based on the $1^{\text {st }}$ layer of the S3 frame, as shown in Fig.3a, to study the effect of strut angle and process parameters on the quality of the printed thin frames. Meanwhile, a complete model was also constructed with dimensions deemed to be used in the actual S3 frame. The settings of key features of the TM and S3 frames are listed in Table 2.

Table 2. The settings of key features of TM and S3 frames. 


\begin{tabular}{cccc|l}
\hline Features & $\begin{array}{c}\text { strutWidth } \\
\text { *strutThick }(\mathrm{mm})\end{array}$ & $\begin{array}{c}\text { strutAngle } \\
\left({ }^{\circ}\right)\end{array}$ & $\begin{array}{c}\text { strutLowVert } \\
(\mathrm{mm})\end{array}$ & $\begin{array}{l}\text { valveRadius }=13 \mathrm{~mm} \\
\text { strutHighVert }=4 \mathrm{~mm} \\
\text { slotWidth }=1 \mathrm{~mm}\end{array}$ \\
TM1 & $0.4 * 0.4$ & $60,63,66$, & 5 & \\
TM2 & $0.3 * 0.3,0.4 * 0.4$, & 60 & 5 & $\begin{array}{l}\text { intRia }=0.1 \mathrm{~mm} \\
\text { extRia }=0.2 \mathrm{~mm} \\
\text { crownOffset }=0.4 \mathrm{~mm}\end{array}$ \\
S3 & $0.5 * 0.5$ & 55 & 2 & \\
\hline
\end{tabular}

\subsection{Material}

316L stainless steel (EN 1.4404) was chosen as the printing material due to its low material cost, good biocompatibility and high process maturity. The 316L SS powder was supplied by LPW Technology Ltd (Carpenter Additive, US) with the gas atomisation technology. The powder particles have a spherical morphology with a Gaussian size distribution ranging from $10 \mu \mathrm{m}$ to $45 \mu \mathrm{m}$. Table 3 shows the chemical composition of 316L SS used in this study.

Table 3. Chemical composition of 316L SS.

\begin{tabular}{ccccccccccc}
\hline Composition & $\mathrm{C}$ & $\mathrm{Si}$ & $\mathrm{Mn}$ & $\mathrm{P}$ & $\mathrm{S}$ & $\mathrm{Cr}$ & $\mathrm{Ni}$ & $\mathrm{Mo}$ & $\mathrm{N}$ & $\mathrm{Fe}$ \\
\hline w.t.\% & 0.02 & 0.82 & 1.33 & 0.006 & 0.004 & 18.2 & 11.9 & 2.2 & $<0.1$ & Bal. \\
\hline
\end{tabular}

\subsection{LPBF process}

The MySint 100 metal AM system (SISMA S.p.A., Italy) was used for the printing of samples. The system has a cylindrical build volume with a diameter of $100 \mathrm{~mm}$ and a height of $100 \mathrm{~mm}$. The laser equipped in the system is a $200 \mathrm{~W}$ fibre laser and the laser beam spot diameter is $55 \mu \mathrm{m}$. The whole printing process was protected by argon gas with an oxygen concentration below $0.3 \%$. The layer thickness $d_{L}$ was $20 \mu \mathrm{m}$. Since the cross-sectional area of struts is very small, there is almost no space for conventional filling vectors as used in the manufacture of large parts. The laser scan vectors shrank with a $75 \mu \mathrm{m}$ beam compensation, $d_{c}$ to guarantee the dimensional accuracy of the struts. This effect is discussed in section 4 with reference to Fig.13a. Different numbers of concentric borders were used to fill the sliced struts. For $0.3 \mathrm{~mm}, 0.4 \mathrm{~mm}$ and $0.5 \mathrm{~mm}$ struts, the numbers of borders were 1,2 and 4 , respectively. The distance between the laser scan vectors was $35 \mu \mathrm{m}$. The other process parameters for TM1, TM2 and S3 frames are listed in Table 4. TM1 and S3 frames were fabricated with the same process parameters. TM2 samples were fabricated with different laser powers, $P(103-123 \mathrm{~W})$ in Group1 and scan speeds, $V(600-800 \mathrm{~mm} / \mathrm{s})$ in Group2. Fig.3a shows the test model with supports on the printing platform. Fig3.b illustrates the printed TM2 frames still fixed on the metal build plates.

Table 4. Process parameters for TM and S3 frames.

\begin{tabular}{|c|c|c|c|c|}
\hline \multicolumn{2}{|c|}{ Sample } & Laser power $(\mathrm{W})$ & Scan speed $(\mathrm{mm} / \mathrm{s})$ & \multirow{5}{*}{$\begin{array}{l}\text { Layer thickness of } 20 \mu \mathrm{m} \\
\text { Border scan without } \\
\text { filling scan }\end{array}$} \\
\hline \multicolumn{2}{|c|}{ TM1 } & 113 & 700 & \\
\hline \multirow{3}{*}{ TM2 } & Group1 & $103,108,113,118,123$ & 700 & \\
\hline & Group2 & 113 & $600,650,700,750,800$ & \\
\hline & S3 & 113 & 700 & \\
\hline
\end{tabular}



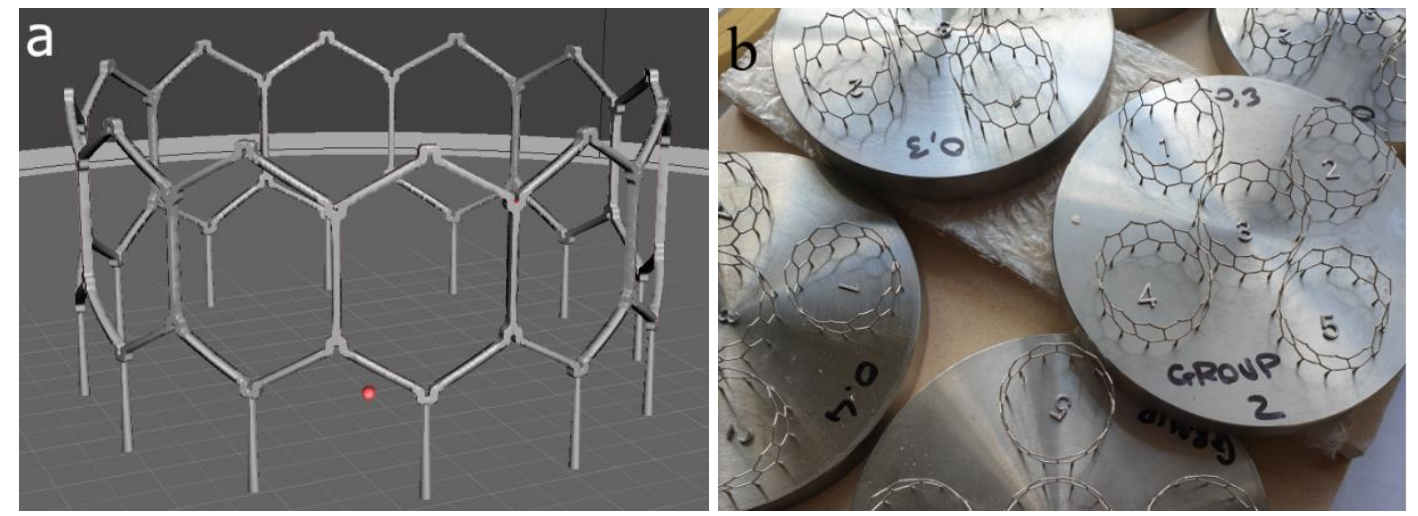

Figure 3. (a) One TM2 model with supports on the printing platform in MeshMixer (Autodesk, Inc.,

US) and (b) TM2 frames on the metal build plates. Five samples were printed for each strut width.

\subsection{Characterization}

The struts of the frames were measured six times with a digital calliper. The average strut width was recorded and compared with the original CAD design. The surface morphology of the frames was examined with the Alicona 3D optical microscope system (Bruker Alicona, Austria). Furthermore, an optical profilometer with a width of $17.519 \mu \mathrm{m}$ was used to scan the surface of the struts following ISO standard 4288-1996. The path length was at least $30 \mathrm{~mm}$ to achieve reliable surface roughness data. Finally, the surface roughness was automatically calculated via the surface profiles in the IFMEASURESUITE software (Bruker Alicona, Austria). The surface roughness of different surfaces was examined for three times with randomly selected struts.

The as-built S3 frame was scanned by a custom Nikon XTEK XTH $225 \mathrm{kVp}$ micro-focus CT system in the $\mu$-VIS lab at the University of Southampton. The beam voltage was set as $200 \mathrm{kV}$ while the current was $115 \mu \mathrm{A} .3142$ projections were taken through 360 degrees with an exposure of $177 \mathrm{~ms}$. The voxel resolution was $16 \mu \mathrm{m}$. Segmentation and geometry reconstruction was performed using Avizo Software (Thermo Fisher Scientific, US) and the exported model was compared with the original CAD model in GOM Inspect 2019 (Carl Zeiss AG, German).

\section{Results}

\subsection{TM1 samples}

Fig.4a shows the TM1 frames removed from the build plate. No breakages of struts were observed in the frames. Fig $4 \mathrm{~b}$ depicts the width of struts of the Batch 1 frames. For the vertical struts, there is minimal effect of strut angle on the manufactured width of the struts, varying between $0.372 \pm 0.01 \mathrm{~mm}$ and $0.387 \pm 0.012 \mathrm{~mm}$. Thus, the dimensional error of the vertical struts is between $3.3 \%$ and $8.8 \%$ with a strut angle ranging from $60^{\circ}$ to $75^{\circ}$. However, the width of the inclined struts generally increases with strut angle. The width of inclined struts is $0.6 \pm 0.043 \mathrm{~mm}$ when the strut angle is $60^{\circ}$. The strut width increases to $0.628 \pm 0.054$ with a strut angle of $63^{\circ}$ and fluctuates around $0.75 \mathrm{~mm}$ with a strut angle from $66^{\circ}$ to $72^{\circ}$. The strut width reaches a maximum of $0.817 \pm 0.075 \mathrm{~mm}$ with a strut angle of $75^{\circ}$. Compared with the vertical struts, the inclined struts have a much larger dimensional error from $50 \%$ 
to $104 \%$ as the strut angle increases from $60^{\circ}$ to $75^{\circ}$. Furthermore, the dimensional deviation of the inclined struts is 5-10 times higher than that of the vertical struts. This indicates high manufacturing irregularities resulting from struts at these selected angles.
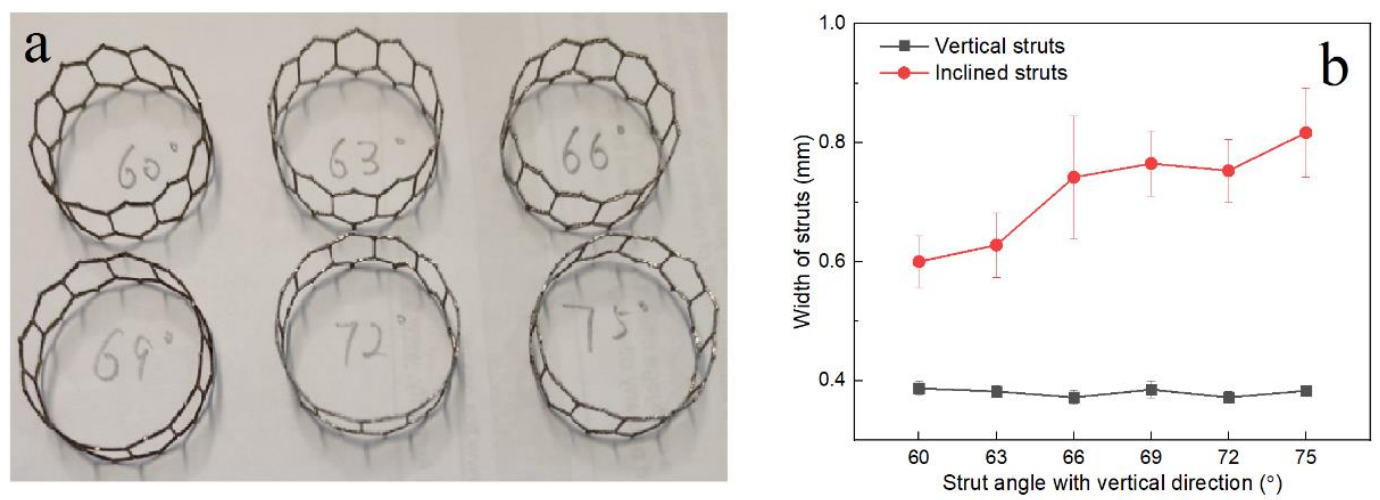

Figure 4. (a) TM1 frames removed from the build plate, and (b) variation of the width of vertical and inclined struts of TM1 frames.

Fig.5 illustrates the side view of the TM1 frames. The arrow in Fig.5a shows the build direction. At the down-skin surfaces, some particles are partially melted and sintered to the struts as shown in the red circles. With the increase of strut angle, more partially melted particles and dross are observed on downskin surfaces as illustrated Fig.5 b-f. However, the up-skin surfaces are much smoother with few splash drops compared with the down-skin surfaces. What's more, the inclined struts become more irregular with the increase of strut angle as illustrated in Fig.5a-f. All the vertical struts show good geometry consistency with a width close to $0.4 \mathrm{~mm}$. However, the irregular surfaces of the inclined struts lead to larger measured widths, which is consistent with the data shown in Fig.4b. Fig.6 a-c depict the 3D surface morphologies of the TM1 frame with $60^{\circ}$ strut angle. The colour map shows the variation of the height of the strut surface in the coordinate system of Alicona microscope. As for the up-skin surface, the height value of the surface is generally between $12 \mathrm{~mm}$ and $12.3 \mathrm{~mm}$. The side surface has a height between $27.3 \mathrm{~mm}$ and $27.5 \mathrm{~mm}$, and the down-skin surface has a larger height variation from $10.2 \mathrm{~mm}$ to $10.8 \mathrm{~mm}$. The gradual colour change in Fig.6a and Fig.6b could be attributed to the imperfect alignment between strut surface and the optical focus surface. The local colour contrast between valleys and peaks could be used to compare the surface quality of different surfaces. It's clear that the side surface is smoothest with smallest height variation between valleys and peaks. The down-skin surfaces are much rougher compared to the side surface and up-skin surface. The surface roughness was calculated based on the surface profiles and plotted in Fig.6d. The side surface roughness is not likely to be affected by the strut angle. The side surface roughness fluctuates in a narrow zone between Ra 7.3 $\mu \mathrm{m}$ and $\mathrm{Ra} 11.3 \mu \mathrm{m}$. However, the up-skin surface roughness increases, varying between Ra $17.7 \pm 2.8$ $\mu \mathrm{m}$ and $\mathrm{Ra} 28.6 \pm 5.7 \mu \mathrm{m}$ when the strut angle increases from $60^{\circ}$ to $75^{\circ}$. The down-skin surface roughness is $\mathrm{Ra} 32.6 \pm 11.1 \mu \mathrm{m}$ with a $60^{\circ}$ strut angle. The down-skin surface roughness increases with the strut angle. The surface roughness reaches Ra $58.9 \pm 13.5 \mu \mathrm{m}$ with $72^{\circ}$ inclined struts and stays at a 
high surface roughness of Ra $57.2 \pm 10.8 \mu \mathrm{m}$ with $75^{\circ}$ inclined struts. The surface roughness values are summarised in Table 5.

Table 5. Surface roughness of TM1 frames.

\begin{tabular}{ccccccc}
\hline \multirow{2}{*}{ Strut angle $\left({ }^{\circ}\right)$} & 60 & 63 & 66 & 69 & 72 & 75 \\
\hline Side surface & $8.2 \pm 0.06$ & $8.4 \pm 1.23$ & $7.3 \pm 0.95$ & $9.5 \pm 0.81$ & $11.3 \pm 2.29$ & $9.4 \pm 2.24$ \\
Up-skin surface & $17.7 \pm 2.76$ & $19.7 \pm 0.94$ & $21.3 \pm 4.76$ & $23.2 \pm 3.36$ & $23.8 \pm 2.36$ & $28.6 \pm 5.66$ \\
Down-skin surface & $32.6 \pm 11.06$ & $35.1 \pm 13.85$ & $46.2 \pm 14.29$ & $53.1 \pm 5.26$ & $58.9 \pm 13.45$ & $57.2 \pm 10.83$ \\
\hline
\end{tabular}
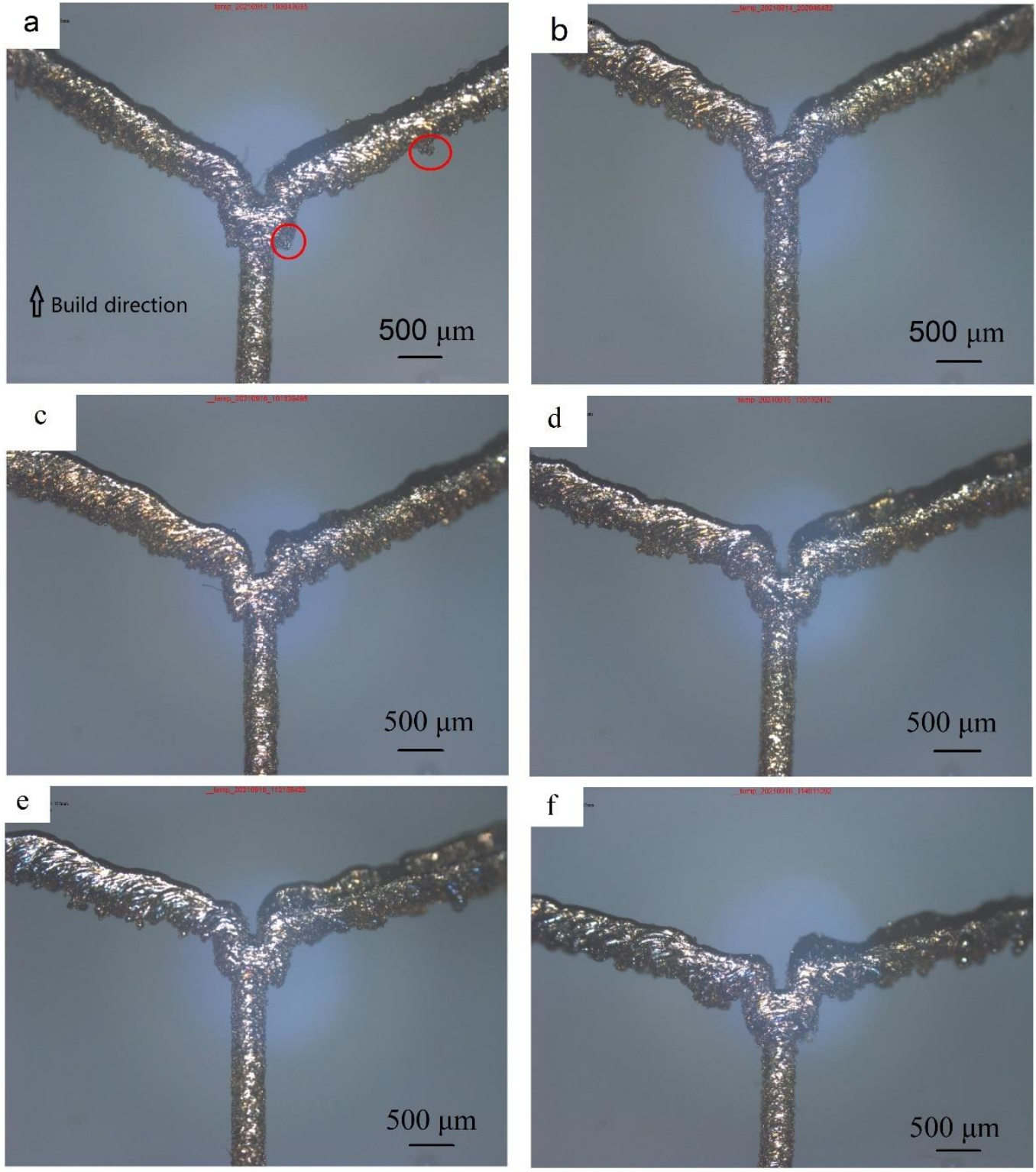

Figure 5. Side view of the TM1 frames with (a) $60^{\circ}$, (b) $63^{\circ}$, (c) $66^{\circ}$, (d) $69^{\circ}$, (e) $72^{\circ}$ and (f) $75^{\circ}$ strut angles. 

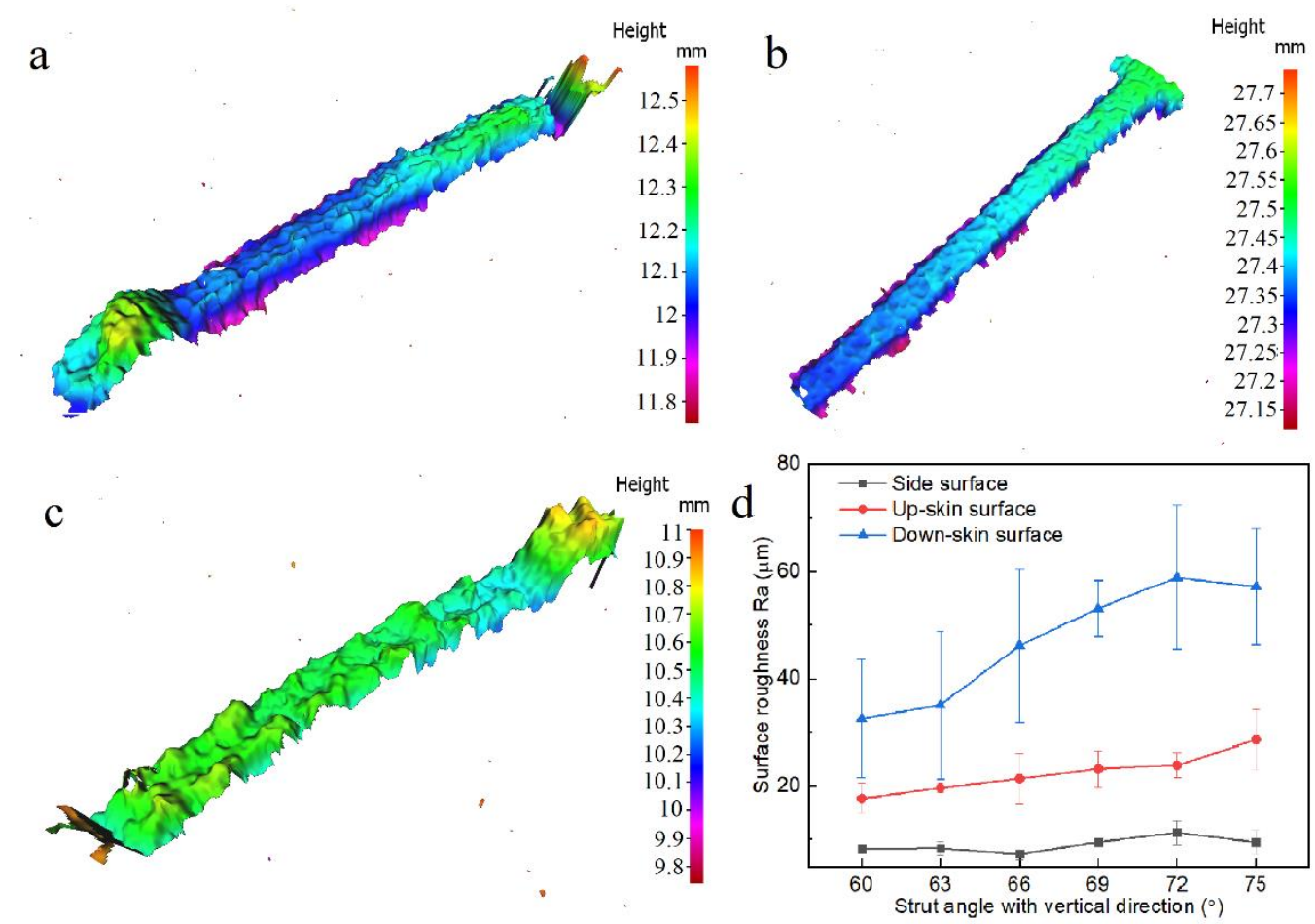

Figure 6. 3D surface morphologies of (a) up-skin surface, (b) side surface, and (c) down-skin surface of TM1 frame with $60^{\circ}$ strut angle, and (d) surface roughness of the TM1 frames.

\subsection{TM2 samples}

Two of the TM2 frames with $0.3 \mathrm{~mm}$ struts were observed to have broken cells as shown in Fig. $3 \mathrm{~b}$. The process parameters used were $600 \mathrm{~mm} / \mathrm{s}$ and $650 \mathrm{~mm} / \mathrm{s}$ with fixed laser power of $113 \mathrm{~W}$. All the remaining frames were in good condition. The average measured strut widths of TM2 frames are plotted in Fig.7. Both laser power and scan speed have a slight effect on the width of vertical struts compared with that on the width of inclined struts. As shown in Fig.7a and Fig.7c, vertical struts have good consistent dimensional size with the original CAD design. The dimensional errors are between $-5 \mu \mathrm{m}$ and $37 \mu \mathrm{m}$ with selected laser powers, and similar dimensional errors between $-7 \mu \mathrm{m}$ and $35 \mu \mathrm{m}$ are observed with the variation of scan speed. The width error of vertical struts, barring a few exceptions, slightly increases with laser power but decreases with scan speed. It can be concluded that the $0.3 \mathrm{~mm}$ vertical struts have a high dimensional accuracy. However, the dimensional error of vertical struts increases as the TM2 frames became thicker from $0.3 \mathrm{~mm}$ to $0.5 \mathrm{~mm}$. As for the inclined strut, the width increased significantly with laser power except the $0.4 \mathrm{~mm}$ and $0.5 \mathrm{~mm}$ struts with $108 \mathrm{~W}$. As illustrated in Fig. $7 \mathrm{~b}$, the dimensional error of the $0.3 \mathrm{~mm}$ inclined struts is between $0.212 \mathrm{~mm}$ to $0.433 \mathrm{~mm}$, namely $71 \%-144 \%$ of the designed width. The dimensional error is $36-97 \%$ for $0.4 \mathrm{~mm}$ frames, while it is $20 \%-$ $61 \%$ for $0.5 \mathrm{~mm}$ frames. As for the effects of scan speed, the dimensional error decreases at specific scan speeds and then increases, except for the $0.4 \mathrm{~mm}$ frames, as shown in Fig.7d. The dimensional error of inclined struts is $84 \%-126 \%, 42 \%-77 \%$ and $20 \%-44 \%$ for $0.3 \mathrm{~mm}, 0.4 \mathrm{~mm}$ and $0.5 \mathrm{~mm}$ struts, respectively. 

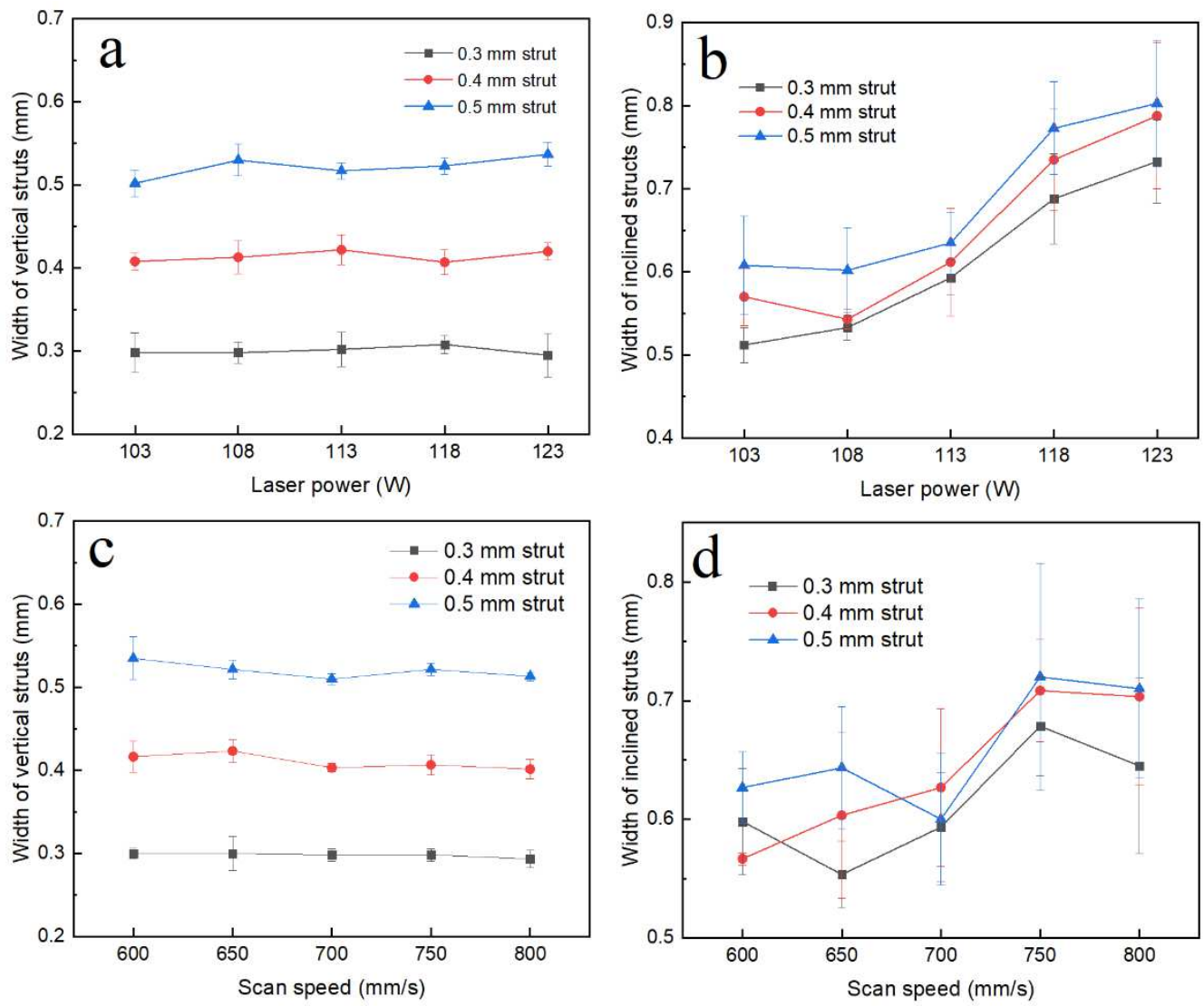

Figure 7. Variation of the strut width of TM2 frames: (a) the vertical and (b) inclined struts with different laser powers, (c) the vertical and (d) inclined struts with different scan speeds.

Fig. 8 depicts the 3D surface morphologies of three TM2 frames with a laser power of $103 \mathrm{~W}$ and a scan speed of $700 \mathrm{~mm} / \mathrm{s}$. The large colour differences along the struts observed in Fig.8a up-skin surface and Fig. $8 \mathrm{c}$ down-skin surface, indicate an imperfect alignment between strut surface and the optical focus surface. The centre of the struts is generally marginally lower than the edge, which is consistent with the border scan strategy. When the strut thickness is $0.3 \mathrm{~mm}$, a balling effect can be observed at the left side of the strut as shown in the up-skin surface of Fig.8a. The up-skin surface is generally rougher than side surface but smoother than the down-skin surface. As the strut becomes thicker, all the surfaces generally become smoother as shown in Fig.8. 


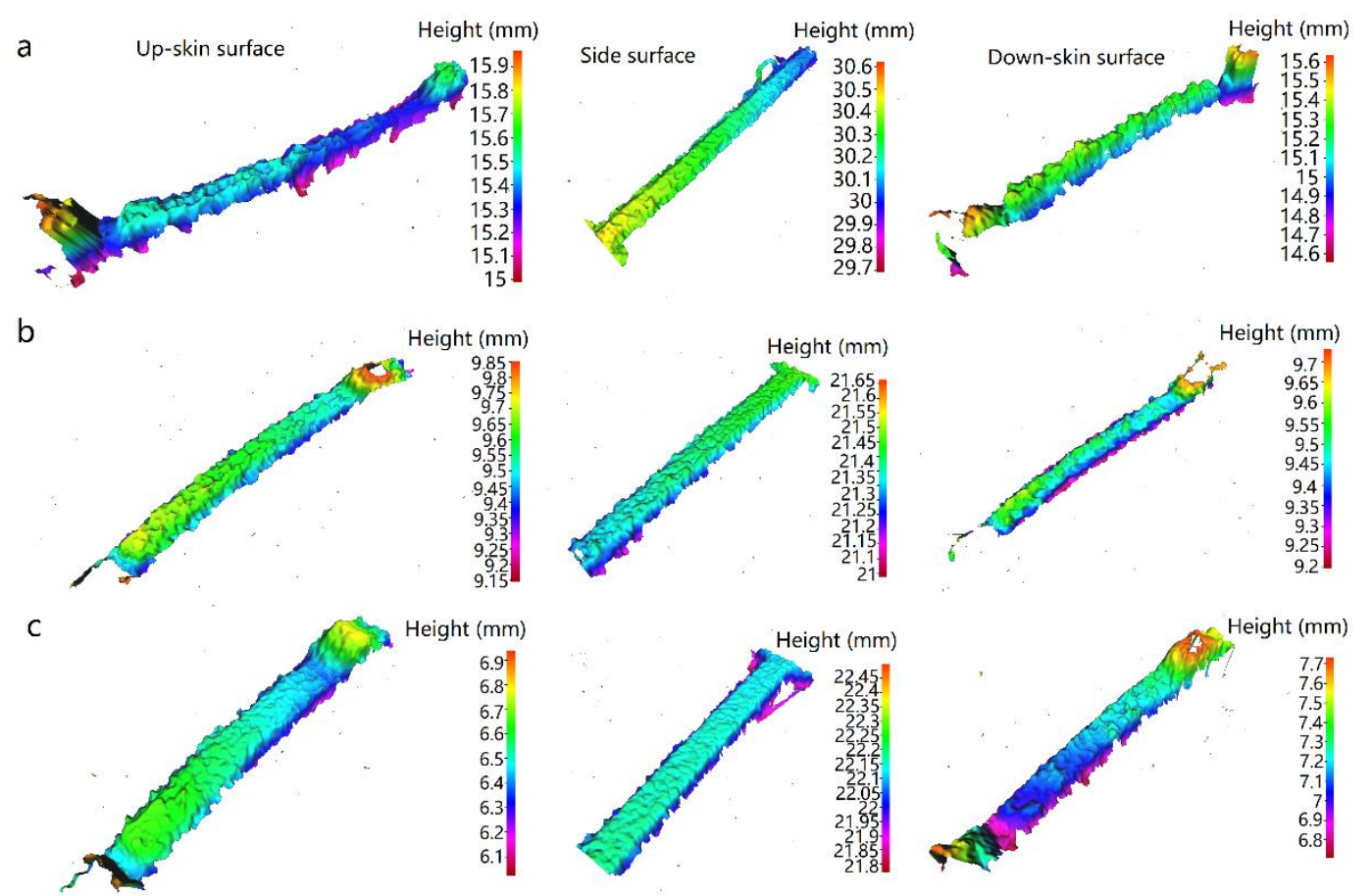

Figure 8. 3D surface morphologies of three TM2 frames with a strut size of (a) $0.3 \mathrm{~mm}$, (b) $0.4 \mathrm{~mm}$ and (c) $0.5 \mathrm{~mm}$. The process parameters used are $113 \mathrm{~W}$ and $700 \mathrm{~mm} / \mathrm{s}$.

Fig.9 plots the variations of surface roughness of the TM2 frames with different laser powers, scan speeds and strut widths. As shown in Fig.9a, the up-skin surface roughness of $0.3 \mathrm{~mm}$ struts gradually decreases with higher laser power than $103 \mathrm{~W}$, but increases with $123 \mathrm{~W}$. The maximum surface roughness is $\mathrm{Ra} 24.7 \pm 3.1 \mu \mathrm{m}$, as the minimum is $\mathrm{Ra} 12.4 \pm 0.6 \mu \mathrm{m}$. As for $0.4 \mathrm{~mm}$ and $0.5 \mathrm{~mm}$ struts, the top surface roughness shows similar increase-then-decrease trend with some exceptions. The surface roughness is generally smaller than that of $0.3 \mathrm{~mm}$ struts. The minimum surface roughness of $\mathrm{Ra}$ $7.7 \pm 1.9 \mu \mathrm{m}$ is achieved with $113 \mathrm{~W}$ and $0.5 \mathrm{~mm}$ thickness. Compared with the up-skin surfaces, the side surfaces have a smaller surface roughness between $\operatorname{Ra} 5 \mu \mathrm{m}$ and $\mathrm{Ra} 12 \mu \mathrm{m}$. However, there is no evidence that the strut size affects the side surface roughness as illustrated in Fig.9b. Fig.9c depicts the surface roughness of down-skin surfaces with different laser powers. Generally, the bottom surfaces are much rougher than the top surface and side surface. The surface roughness is between $\mathrm{Ra} 22.7 \pm 1.3 \mu \mathrm{m}$ and Ra 53.7 $\pm 14.1 \mu \mathrm{m}$. Similar to the top surface, the bottom surface roughness is prone to be smaller with a thicker strut. The variation of surface roughness with different scan speeds is plotted in Fig.8 df. As for the up-skin surface, the surface roughness varies less with faster scan speed compared with the effects of laser power. The side surface roughness is generally within a narrow range except $0.3 \mathrm{~mm}$ strut with $700 \mathrm{~mm} / \mathrm{s}$ and $0.5 \mathrm{~mm}$ strut with $650 \mathrm{~mm} / \mathrm{s}$. The down-skin surface roughness of $0.3 \mathrm{~mm}$ struts increases from Ra $36.3 \pm 2.5 \mu \mathrm{m}$ to $\mathrm{Ra} 46.1 \pm 11.1 \mu \mathrm{m}$ as the scan speed increases from $600 \mathrm{~mm} / \mathrm{s}$ to $800 \mathrm{~mm} / \mathrm{s}$. However, the bottom surface roughness of $0.4 \mathrm{~mm}$ and $0.5 \mathrm{~mm}$ stays between Ra $21 \mu \mathrm{m}$ and $\operatorname{Ra} 27 \mu \mathrm{m}$. Although the surface roughness data is very large and complex, some features of the surface quality can be summarised as follows: (a) the side surface is smoothest and the down-skin 
surface has the largest surface roughness, (2) laser power and scan speed have larger effects on the surface quality of the up-skin and down-skin surfaces than that of the side surface, (3) a thicker strut helps to improve the surface quality.
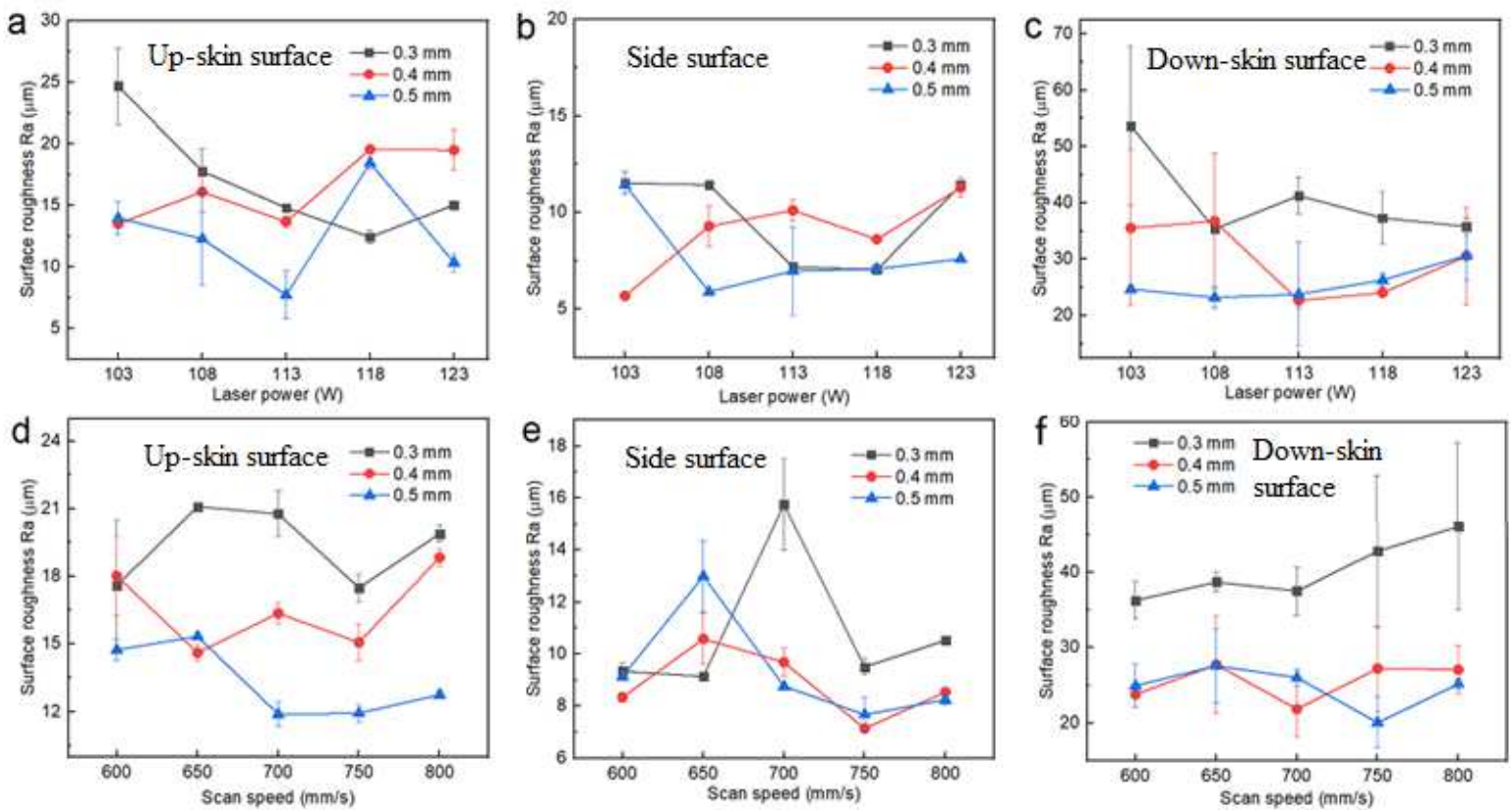

Figure 9. Surface roughness of TM2 frames with (a-c) different laser powers and (d-f) scan speeds.

\subsection{S3 frame}

Fig.10a depicts the as-built S3 frame removed from the build plate. During manual removal from the plate, there were no strut breakages but the $1^{\text {st }}$ layer of cells was slightly distorted. Fig.10b shows the computational model of the S3 frame, generated from the high resolution CT scan of the frame, and Fig.10c depicts the pores in the S3 frame as measured using Avizo software. The CAD model volume of the frame is $94.16 \mathrm{~mm}^{3}$ and the volume of pores is $0.52 \mathrm{~mm}^{3}$. Thus, the porosity of the as-built S3 frame is $0.55 \%$. Most of the pores are found in the inclined struts, crowns, and assembly slots, as no pores are found in the vertical struts. Based on the analysis of the pores in Avizo software, there are 3033 pores. From the pore size distribution as shown in Fig.10d, most of the pores have smaller size than $0.1 \mathrm{~mm}$. The minimum equivalent pore size is $0.018 \mathrm{~mm}$ and the maximum pore size is $0.415 \mathrm{~mm}$, which is located in the large sections close to the leaflet assembly slots as shown in Fig.10c. Meanwhile, most pores were generally found in the centre of the strut cross-sections. This is attributed to the scan strategy used wherein the struts were scanned with two concentric border scans. The CT results suggest that the melt tracks didn't have sufficient overlap to avoid the creation of pores. 

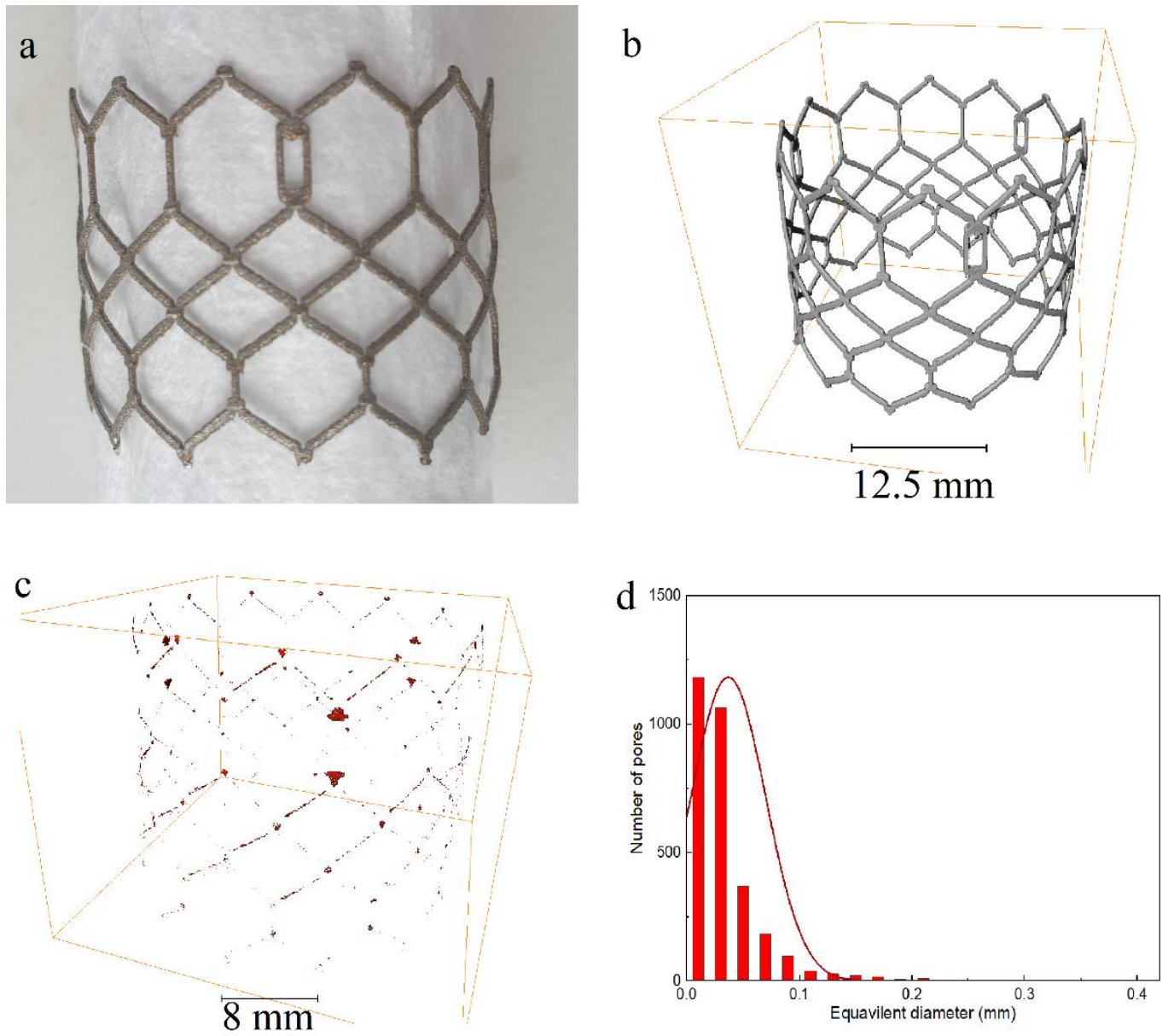

Figure 10. (a) As-built S3 frame, (b) the reconstructed S3 frame, (c) internal pores in S3 frame, and (d) pore size distribution in S3 frame.

The reconstructed S3 model was exported as a STL file from the Avizo software. Since the STL model is too large to be auto-aligned in GOM Inspect 2019, the initial alignment between the STL file and the designed CAD model was conducted in Rhino. Then, the local best-fit alignment was used in GOM Inspect 2019. The assembly slots were chosen as the target area for alignment. Fig.11a shows the final alignment result. Fig.11b depicts deviation distribution between the printed frame and the design. In both sub-figures, the $1^{\text {st }}$ layer of cells has large deviations due to the distortion of the frame when removing it from the build plate. The distortion also causes deviations of adjacent cells in the $2^{\text {nd }}$ and $3^{\text {rd }}$ layers. Also, the top crowns have larger deviations $(0.31 \mathrm{~mm})$ compared to the middle cells $(0.04$ $\mathrm{mm})$. Fig. 11c illustrates the $0.5 \mathrm{~mm}$ tolerance distribution on the frame. The red regions highlight where geometric deviation is larger than $0.5 \mathrm{~mm}$. These include the up-skin and down-skin surfaces of the inclined struts, and overhanging surfaces of the leaflet assembly slots, which can be attributed to the large dimensional error described in section 3.1 and 3.2. 

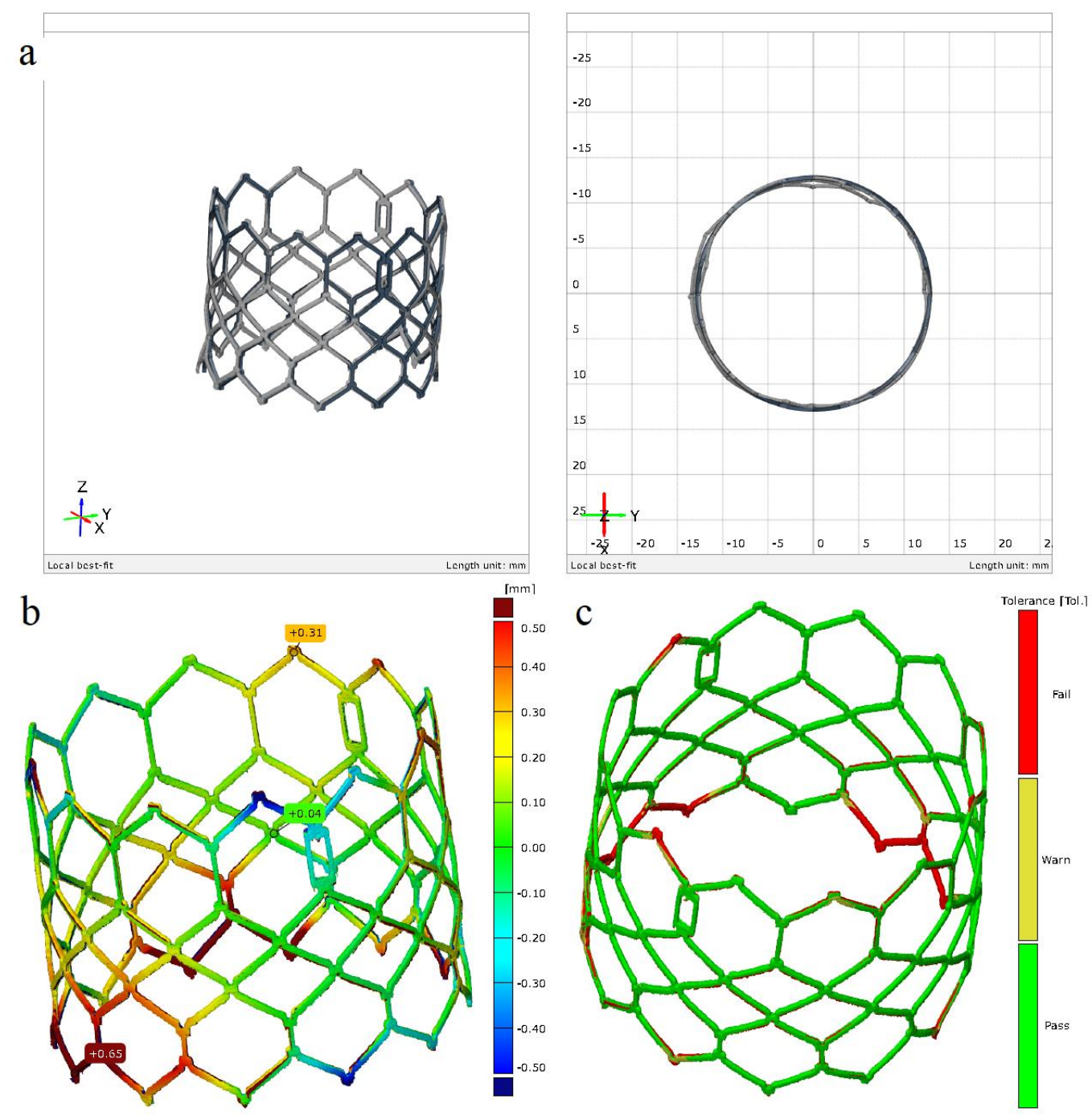

Figure 11. (a) The final alignment between the original CAD model and the model constructed from the CT scan from angled view and plan view, (b) deviation distribution and (c) $0.5 \mathrm{~mm}$ tolerance distribution on the printed frame.

\section{Discussion}

Due to the layer-by-layer manufacturing fashion of LPBF, the dimensional accuracy and surface quality of as-built parts are significantly affected by the characteristics of a single melt track and the scan strategy to stack the melt tracks. Since the frame struts are relatively thin, it's difficult to prepare metallurgical samples to observe the cross-section of the struts. Mathematical methods have been used to explore and understand the fundamental behavior of the single melt track in LPBF. The Rosenthal model was first developed in 1941 to evaluate the thermal field during arc welding [27]. Recently it has been used to predict the thermal field and melt track geometry of parts fabricated with LPBF due its simplicity and wide applicability $[28,29]$. In this study, a MATLAB program was used to calculate the thermal field of a single melt track based on the Rosenthal model. Table 6 lists the material properties used in the calculation. 
Table 6. Material properties used in the calculation.

\begin{tabular}{cccc}
\hline & Value & Unit & Ref. \\
\hline Melting point, $T_{M}$ & 1385 & ${ }^{\circ} \mathrm{C}$ & {$[30]$} \\
Thermal conductivity, $\kappa$ & 12.45 & $\mathrm{~W} / \mathrm{mK}$ & {$[31]$} \\
Specific heat, $c_{p}$ & 468 & $\mathrm{~J} / \mathrm{kgK}$ & {$[31]$} \\
Thermal diffusivity, $\alpha$ & $3.4 \times 10^{-6}$ & $\mathrm{~m}^{2} / \mathrm{s}$ & {$[31]$} \\
Absorptivity, $\varepsilon$ & 0.58 & & {$[32]$} \\
\hline
\end{tabular}

Fig.12a depicts the temperature contour and melt track boundary of a single melt track using $113 \mathrm{~W}$ and $700 \mathrm{~mm} / \mathrm{s}$, obtained using the MATLAB calculation from The MathWorks, Inc. (US). The width of the melt track is $131.4 \mu \mathrm{m}$, while the depth is $65.7 \mu \mathrm{m}$. As shown in Fig.12b, the width and depth of the melt track increases linearly with the increase of laser power. The width and depth of the melt track vary, respectively, between $125.3 \mu \mathrm{m}$ and $137.2 \mu \mathrm{m}$, and $62.6 \mu \mathrm{m}$ and $68.6 \mu \mathrm{m}$. With respect to variation of the scan speed between $600 \mathrm{~mm} / \mathrm{s}$ to $800 \mathrm{~mm} / \mathrm{s}$ (Fig.12c), the width of the melt track decreases linearly from $141.7 \mu \mathrm{m}$ to $123 \mu \mathrm{m}$ whilst the depth decreases from $70.8 \mu \mathrm{m}$ to $61.5 \mu \mathrm{m}$.
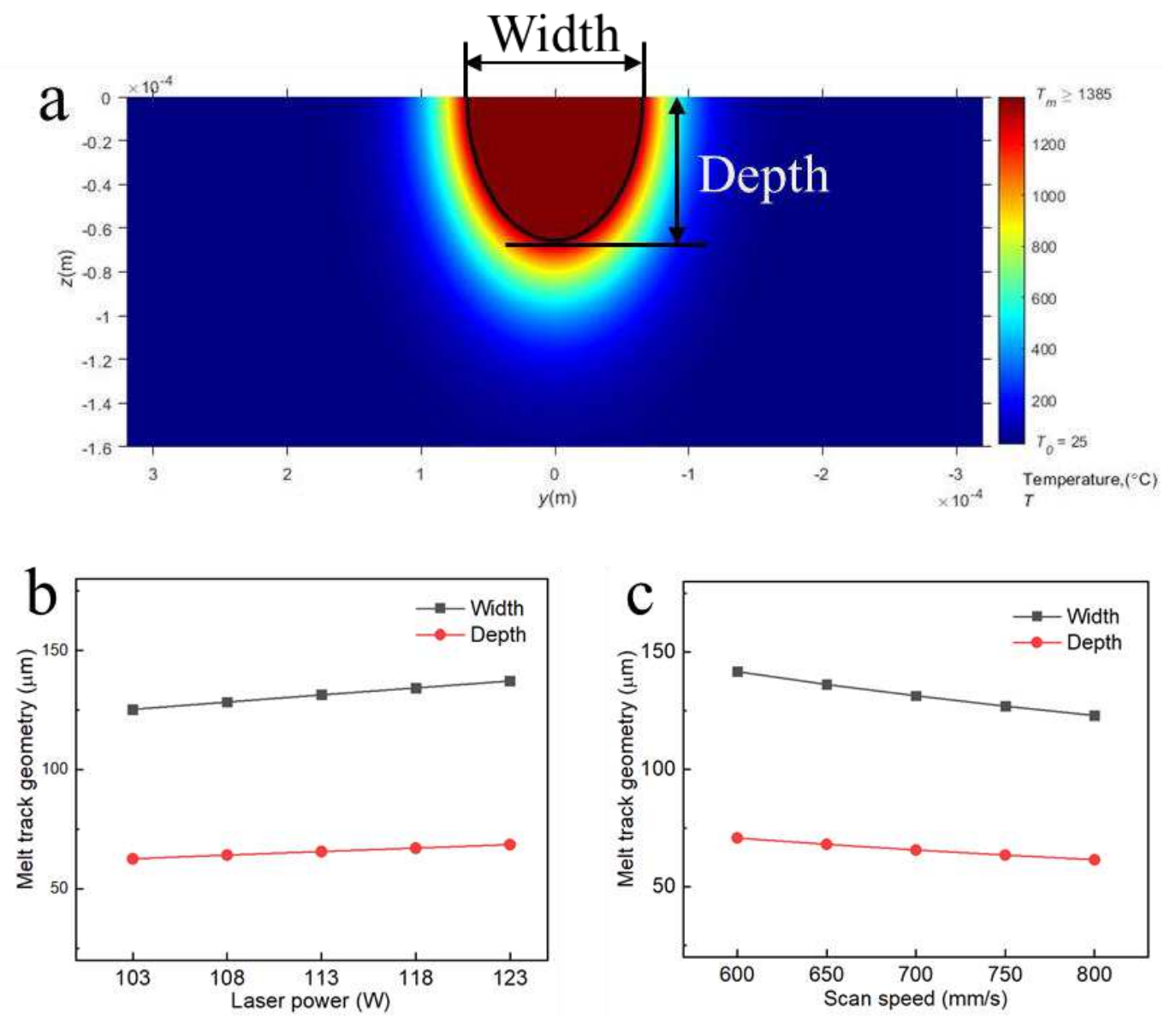

Figure 12. Melt track boundary simulated with a laser power of $113 \mathrm{~W}$ and a scan speed of $700 \mathrm{~mm} / \mathrm{s}$ (a) Cross-sectional view of the temperature contour, (b) variation of width and depth with laser power and (c) variation of width and depth with scan speed. 
Fig.13a and Fig.13b schematically illustrate the border scan strategy for vertical struts and inclined struts. The cross-sections of struts are simplified as square and rectangle shapes due to the large ratio between the strut width and radius of strut curvature. As shown in the top view, the dash lines represent the border of the struts. The vertical struts have a square shape since the width and thickness of struts were set as the same value. The longer side of the cross-section of inclined struts can be calculated as strutWidth/cos(strutAngle), roughly 1.22-3.87 times strutWidth as the strutAngle increases from $55^{\circ}$ to $75^{\circ}$. The cyan solid lines represent the laser scan vectors, and the yellow solid shape is the melt track of the border. The red double arrow represents the laser beam compensation, $\mathrm{d}_{c}$. As shown in the side view of struts, the melt tracks are stacked with the specific layer thickness, $20 \mu \mathrm{m}$. As for the inclined struts, the melt tracks shift in every single layer with an offset of $d_{L} * \tan ($ strutAngle), roughly $28-75 \mu \mathrm{m}$.

a Top view

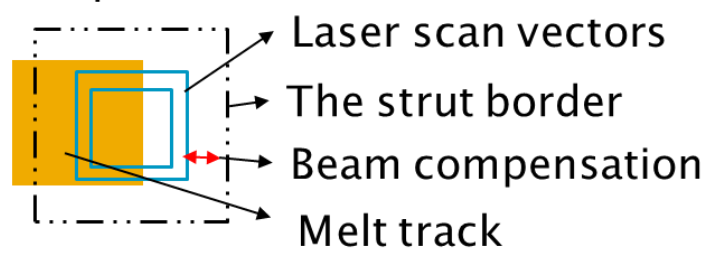

\section{Side view}

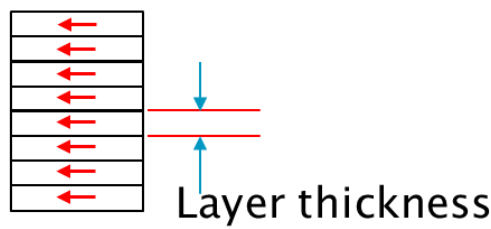

Top view

Side view

b
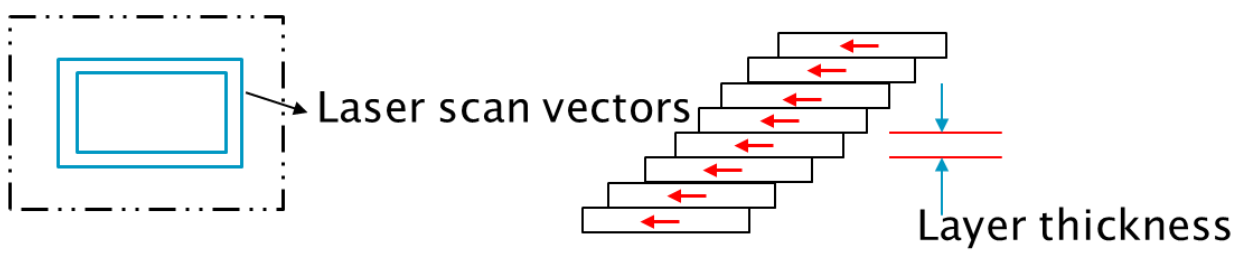

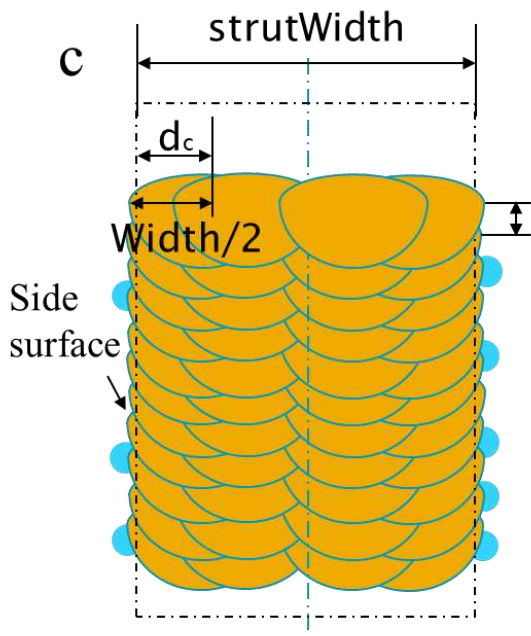

Vertical strut

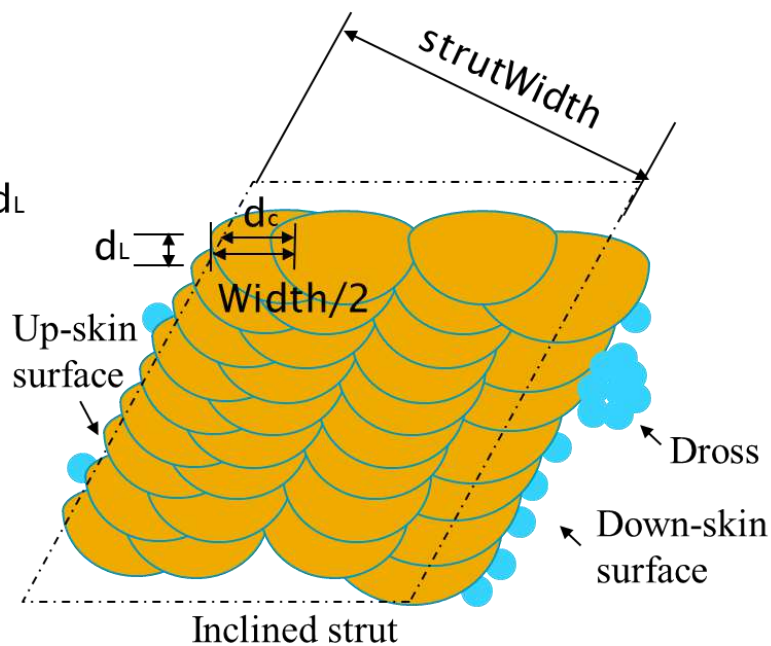

Inclined strut

Figure 13. Schematic diagrams of border scan strategy for (a) vertical struts, (b) inclined struts, and (c) the cross-sectional view of melt tracks in the $0.3 \mathrm{~mm}$ strut. 
Due to the laser beam energy distribution in LPBF, the cross-section of melt tracks is generally symmetric [33]. Fig.13c depicts the cross-sectional view of the melt tracks in the $0.3 \mathrm{~mm}$ strut. Based on the calculated results in Fig.12, the depth of the melt track is much higher than the layer thickness. The melt track tends to re-melt at least three previous layers. The middle of the border melt track has a compensation, $d_{c}$ with the geometry border (dash line). For the vertical struts, the width of vertical strut can be estimated as strutWidth-2d $2 d_{c}+$ width. Based on the calculated results, the width of vertical strut fabricated with $113 \mathrm{~W}$ and $700 \mathrm{~mm} / \mathrm{s}$ is $0.281 \mathrm{~mm}$. The experimental results in TM2 samples are 0.298 $\mathrm{mm}$ and $0.302 \mathrm{~mm}$, which are a little higher than the calculated results. The effects of laser power and scan speed on the vertical strut width are consistent with the calculated results from the Matlab. As for the inclined struts, the slice shifts layer-by-layer as discussed in the previous paragraph. Part of the scan vectors are directly on the powder particles. Compared with the vertical strut, less solid beneath the melt track leads to lower heat conduction [17] and higher sustained temperatures in the melt pool. Thus, more powder particles will be melted and form a larger melt track. The excess melted mass tends to penetrate into the powder particles with the effect of gravity and surface capillary force [34], which forms large dross as shown in Fig.5 b-f and Fig.13c. Meanwhile, the depth of the melt track also causes the severe mismatch of melt tracks and the designed geometry. With the increase of laser power, the melt track becomes wider and deeper, which leads to a larger dimensional error for the inclined struts. However, the effects of scan speed on the strut width doesn't follow the Matlab calculated results. It was found that increasing scan speed gave rise to residual stresses [35], which can worsen the warping effect [36] and cause larger dimensional errors. Furthermore, for the smaller planar cross-section of the vertical strut, the overlaps between melt tracks are higher than the inclined struts and the large crosssection near the assembly slots. When the struts become thicker, the overlaps between melt track become smaller, which could lead to pores being created in the frames. This helps to explain the specific distribution of pores in the S3 frame as illustrated in Fig.10c. Also, thicker struts have better structural stability when interacting with the powder spreader. Thus, the dimensional accuracy is generally better with thicker struts.

Unlike conventional manufacturing technologies, LPBF tends to produce surfaces with several topographical features including micro-scaled surface asperity, wave-like melt track features, form error globules an surface pores [12]. The surface profiles of the side surface, up-skin surface and down-skin surface are also marked in Fig.13c. The wave-like features and form error globules are the main factors to influence the surface roughness in this study. There is minimum variation in the waviness profile of the side surface, but it is higher in the up-skin surface and higher still in the down-skin surface. There are less partially sintered particles on the side surface and up-skin surface due to the lower sustained melt pool temperature. However, many partially melted particles and even large dross can be observed on the down-skin surface, which is also reported in other publications [11, 12, 15, 34]. Thus, the bottom surface is much rougher compared to the other surfaces. When strut thickness increases, there is improved structural stability and, better thermal conduction through the struts helps to reduce the 
surface roughness. The effects of laser power and scan speed variation on the surface roughness is unclear based on our results. However, some basic features of surface quality of thin strut structures have been concluded in section 3.2.

\section{Conclusion}

In this study, the effects of strut dimensions and angles, laser power and scan speed on the dimensional accuracy and surface quality of the thin struts, that make up a typical frame for a replacement heart valve, were systemically studied. The results can be concluded as follows:

1) Thin strut heart valve frames with strut cross-sectional dimensions between $0.3 \mathrm{~mm}$ to $0.5 \mathrm{~mm}$ can be successfully manufactured using laser powder bed fusion, LPBF.

2) Relative to laser power, scan speed and cross-sectional dimensions, the angle of inclined struts has the largest impact on dimensional accuracy and good surface quality. Although a strut angle of $75^{\circ}$ can be achieved by LPBF, a much smaller strut angle is recommended for frames to be manufactured using LPBF.

3) Vertical struts have better dimensional accuracy and surface quality than inclined struts. The down-skin surfaces have the largest surface roughness, in excess of Ra $20 \mu \mathrm{m}$. All frames analysed here have not been treated using sand blasting, polishing or any other post process. It's clear that surface treatment will be necessary to achieve the high surface quality needed for replacement heart valves.

4) The complete $\mathrm{S} 3$ frame had a low porosity of $0.55 \%$ and a generally good dimensional accuracy when compared to the original computer model. However, improvements are required for inclined struts and overhanging surfaces such as those found in the leaflet assembly slots.

\section{Acknowledgement}

This work was supported by the Engineering and Physical Sciences Research Council (EPSRC, UK), [Grant No. EP/S030182/1]. The authors acknowledge the $\mu$-VIS X-ray Imaging Centre (supported by EPSRC grant EP/H01506X/1) and the Biomedical Imaging Unit at the University of Southampton, for the provision of imaging, data processing and management infrastructure and expertise.

\section{References}

[1] Murr LE (2018) Additive manufacturing of biomedical devices: an overview. Mater Technol 33:57-70. https://doi.org/10.1080/10667857.2017.1389052

[2] Zhao X, Wei QS, Gao N, Zheng EL, Shi YS, Yang SF (2019) Rapid fabrication of TiN/AISI 420 stainless steel composite by selective laser melting additive manufacturing. J Mater Process Tech 270:8-19. https://doi.org/10.1016/j.jmatprotec.2019.01.028

[3] Walker JM, Haberland C, Andani MT, Karaca HE, Dean D, Elahinia M (2016) Process development and characterization of additively manufactured nickel-titanium shape memory parts. J Intel Mat Syst Str 27:2653-2660. https://doi.org/10.1177/1045389X16635848 
[4] Song B, Zhao X, Li S, et al (2015) Differences in microstructure and properties between selective laser melting and traditional manufacturing for fabrication of metal parts: A review. Front Mech Eng 10:111-125. https://doi.org/10.1007/s11465-015-0341-2

[5] Liu R, Wang Z, Sparks T, Liou F, Newkirk J (2017) Aerospace applications of laser additive manufacturing. In: Brandt M (ed) Laser additive manufacturing. Woodhead Publishing, Cambridge, pp 351-371. https://doi.org/10.1016/B978-0-08-100433-3.00013-0

[6] Hoye N, Li H, Cuiuri D, Paradowska A (2014) Measurement of residual stresses in titanium aerospace components formed via additive manufacturing. Materials Science Forum 777:124-129. https://doi.org/10.4028/www.scientific.net/msf.777.124

[7] Calignano F, Galati M, Iuliano L, Minetola P (2019) Design of additively manufactured structures for biomedical applications: A review of the additive manufacturing processes applied to the biomedical Sector. J Healthc Eng 2019: 9748212. https://doi.org/10.1155/2019/9748212

[8] Trevisan F, Calignano F, Aversa A, et al (2018) Additive manufacturing of titanium alloys in the biomedical field: processes, properties and applications. J Appl Biomater Func 16:57-67. https://doi.org/10.5301/jabfm.5000371

[9] Lodhi MJK, Deen KM, Greenlee-Wacker MC, Haider W (2019) Additively manufactured 316L stainless steel with improved corrosion resistance and biological response for biomedical applications. Addit Manuf 27:8-19. https://doi.org/10.1016/j.addma.2019.02.005

[10] Kruth JP, Yasa E, Deckers J (2008) Roughness improvement in selective laser melting. Proceedings of the 3rd international conference on polymers and moulds innovations, 170-183.

[11] Calignano F (2018) Investigation of the accuracy and roughness in the laser powder bed fusion process. Virtual Phys Prototyp 13:97-104. https://doi.org/10.1080/17452759.2018.1426368

[12] Lou S, Jiang X, Sun W, Zeng W, Pagani L, Scott PJ (2019) Characterisation methods for powder bed fusion processed surface topography. Precis Eng 57: 1-15.

https://doi.org/10.1016/j.precisioneng.2018.09.007

[13] Khorasani M, Ghasemi A, Awan US, et al (2020) A study on surface morphology and tension in laser powder bed fusion of Ti-6Al-4V. Int J Adv Manuf Tech 111:2891-2909.

https://doi.org/10.1007/s00170-020-06221-w

[14] Guo C, Li S, Shi S, et al (2020) Effect of processing parameters on surface roughness, porosity and cracking of as-built IN738LC parts fabricated by laser powder bed fusion. J Mater Process Tech 285: 116788. 10.1016/j.jmatprotec.2020.116788

[15] Snyder JC, Thole KA (2020) Understanding laser powder bed fusion surface roughness. J Manuf Sci Eng 142:071003. https://doi.org/10.1115/1.4046504

[16] Fox JC, Moylan SP, Lane BM (2016) Effect of process parameters on the surface roughness of overhanging structures in laser powder bed fusion additive manufacturing. Proc CIRP 45:131-134. https://doi.org/10.1016/j.procir.2016.02.347 
[17] Calignano F (2014) Design optimization of supports for overhanging structures in aluminum and titanium alloys by selective laser melting. Mater Design 64: 203-213.

https://doi.org/10.1016/j.matdes.2014.07.043

[18] Tomas J, Hitzler L, Köller M, et al (2020) The dimensional accuracy of thin-walled parts manufactured by laser-powder bed fusion process. J Manuf Mater Process 4:91.

https://doi.org/10.3390/jmmp4030091

[19] Ahmed A, Majeed A, Atta Z, Jia G (2019) Dimensional quality and distortion analysis of thinaalled alloy parts of AlSi10Mg manufactured by selective laser melting. J Manuf Mater Process 3:51. https://doi.org/10.3390/jmmp3020051

[20] Charles A, Elkaseer A, Thijs L, Scholz SG (2020) Dimensional errors due to overhanging features in laser powder bed fusion parts made of Ti-6Al-4V. Appl Sci 10:2416.

https://doi.org/10.3390/app10072416

[21] Wu ZH, Narra SP, Rollett A (2020) Exploring the fabrication limits of thin-wall structures in a laser powder bed fusion process. Int J Adv Manuf Tech 110:191-207. https://doi.org/10.1007/s00170020-05827-4

[22] Safdel A, Elbestawi MA (2021) Distortion and printability of stent structures in laser powder bed fusion processing of NiTi alloys. Mater Lett 300:130163.

https://doi.org/10.1016/j.matlet.2021.130163

[23] Wiesent L, Schultheiß U, Lulla P, et al (2020) Computational analysis of the effects of geometric irregularities and post-processing steps on the mechanical behavior of additively manufactured 316L stainless steel stents. Plos One 15:e0244463. https://doi.org/10.1371/journal.pone.0244463

[24] Giordano A, Biondi-Zoccai G, Frati G (2019) Transcatheter Aortic Valve Implantation: Clinical, Interventional and Surgical Perspectives. Springer, Switzerland

[25] Melancon D, Bagheri ZS, Johnston RB, Liu L, Tanzer M, Pasini D (2017) Mechanical characterization of structurally porous biomaterials built via additive manufacturing: experiments, predictive models, and design maps for load-bearing bone replacement implants. Acta Biomater, 63:350-368. https://doi.org/10.1016/j.actbio.2017.09.013

[26] Zhao X, Bressloff N, Bellin M (2021) Assessment of heart valve frame manufactured by laser powder bed fusion, Trans Addit Manuf Meets Medicine 3:495-495.

https://doi.org/10.18416/AMMM.2021.2109495.

[27] Rosenthal D (1941) Mathematical theory of heat distribution during welding and cutting. Weld J 20:220-234.

[28] Promoppatum P, Yao SC, Pistorius PC, Rollett AD (2017) A comprehensive comparison of the analytical and numerical prediction of the thermal history and solidification microstructure of Inconel 718 products made by laser powder-bed fusion. Engineering 3:685-694.

https://doi.org/10.1016/J.ENG.2017.05.023 
[29] Tang M, Pistorius PC, Beuth JL (2017) Prediction of lack-of-fusion porosity for powder bed fusion. Addit Manuf 14:39-48. https://doi.org/10.1016/j.addma.2016.12.001

[30] Mills KC (2002) Recommended values of thermophysical properties for selected commercial alloys. Woodhead Publishing, Cambridge.

[31] GE Additive (2021) GE Additive 316L Datasheet.

https://www.ge.com/additive/sites/default/files/2019-11/316L-M2beide.pdf. Accessed 1 October 2021.

[32] Rubenchik A, Wu S, Mitchell S, et al (2015) Direct measurements of temperature-dependent laser absorptivity of metal powders. Appl Optics 54:7230-7233.

https://doi.org/10.1364/AO.54.007230

[33] Scime L, Beuth J (2019) Melt pool geometry and morphology variability for the Inconel 718 alloy in a laser powder bed fusion additive manufacturing process. Addit Manuf 29:100830.

https://doi.org/10.1016/j.addma.2019.100830

[34] Tian Y, Tomus D, Rometsch P, Wu X (2017) Influences of processing parameters on surface roughness of Hastelloy X produced by selective laser melting. Addit Manuf 13:103-112.

https://doi.org/10.1016/j.addma.2016.10.010

[35] Mugwagwa L, Yadroitsev I, Matope S (2019) Effect of process parameters on residual stresses, distortions, and porosity in selective laser melting of Maraging steel 300. Met 9:1042.

https://doi.org/10.3390/met9101042

[36] Wang D, Yang YQ, Yi ZH, Su XB (2013) Research on the fabricating quality optimization of the overhanging surface in SLM process. Int J Adv Manuf Tech 65:1471-1484.

https://doi.org/10.1007/s00170-012-4271-4 


\section{Statements \& Declarations}

\section{Funding}

This work was supported by the Engineering and Physical Sciences Research Council (EPSRC, UK), [Grant No. EP/S030182/1].

\section{Competing Interests}

Xiao Zhao, Anqi Liang and Neil W. Bressloff have no relevant financial or non-financial interests to disclose. Matteo Bellin is employed by SISMA S.p.A.

\section{Author Contributions}

Xiao Zhao: Data curation, Writing- Original draft preparation and editing Anqi Liang: MATLAB simulation

Matteo Bellin: Sample preparation and process parameter optimization

Neil W. Bressloff: Supervision and draft reviewing 